\title{
A dynamic approach to determine the product flow nature in apparel supply chain network
}

\author{
Mohammed Marufuzzaman, Ahmed M. Deif* \\ Industrial Systems Engineering, Faculty of Engineering \& Applied Science, University of Regina, Regina, SK, Canada S4S 0A2
}

\begin{abstract}
A B S T R A C T
This paper presents a novel metric, product flow number, to determine the product flow nature across the supply chain of apparel industries. The metric is based on mapping the dynamics of fluid flow across a pipe to product flow across a supply chain. Numerical analysis is conducted to examine the impact of the different metric parameters on the product flow. Results showed that smooth dynamics can be achieved through scaling production and extending delivery times, while undesirable dynamics are tied to complex product designs and increasing number of suppliers. Finally, the paper demonstrated how the new metric can be used as a planning and control tool for supply chain management in the apparel industry.
\end{abstract}

\section{Introduction}

In today's dynamic market and uncertain competing environment, the need for robust supply chains becomes more pressing. Robustness in supply chain management requires both dynamic models as well as adaptive planning and control policies. The service provided to the end customer is determined by the effectiveness and efficiency of the dynamic cooperation of all companies in the supply chain (Souza et al., 2000). Competition is no longer one company against other companies, but one supply chain against other supply chains. Robust supply chain management is highly related to the ability to coordination the goal searching processes of different companies in the supply chain. This is particularly important since companies have their own business goals and rules that may, in some cases, conflict with each other.

Today's supply chains are nonlinear dynamic systems, the control of which is complicated by long, variable delays in product and information flows (Joshi, 1998). The complexity essence of supply chain and the ever-changing market environment have bearing on lots of dynamics, uncertain and complex factors affecting supply chain performance. However, managers mostly pay their attention to some critical performance measure and key variables, such as order fulfilment rate, inventory level and production capacity. Today's market place is increasingly dynamic and volatile. So these factors often change over time. Moreover, there are many feedback loops within these factors which cause complex interrelationships and complex behaviours in supply chain (Wilding, 1998). It is much difficult for supply chain managers to clearly understand various problems in supply chain

\footnotetext{
* Corresponding author. Tel.: +1 306585 4733; fax: +1 3065854855

E-mail addresses: marufuzm@uregina.ca (M. Marufuzzaman), Ahmed.Deif@uregina.ca (A.M. Deif).
}

operations and make appropriate decisions within limited time to improve supply chain performance.

The work presented in this paper contributes to the field of robust supply chain through dynamic performance modeling and analysis. A new metric named as product flow number (PFN) is proposed. The scope of work focuses on the apparel industry without loosing the generality of the proposed approach to other industries. The objective behind developing this number is to better understand and manage the supply chain dynamics through focusing on the product flow. Obviously, it is very helpful to realize quantitative management of supply chain and provide managers with theoretical foundation for decision making so as to achieve continuous performance improvement and collaborative operations of supply chain.

The remainder of this paper is organized as follows: Section 2 reviews the supply chain dynamics. Section 3 introduces the assumptions, the number itself and input parameters of the proposed flow number. Section 4 describes briefly the industrial application to validate the number. Section 5 includes the guidelines for managing apparel supply chain based on the proposed number and finally, in Section 6 some managerial implications of the proposed number are discussed with suggestions for future research.

\section{Review on supply chain dynamics}

Supply chains are complicated dynamic systems triggered by customer demands. Proper selection of equipments, machinery, buildings and transport fleets is a key component for the success of such systems. Companies need to cope up with high seasonal fluctuations in demand. Fast design changes and complex products require special attention in ramp-up to full volume. Several researches have been carried out to explore different dynamic aspects of the supply chain. In this section we review examples of these researches. 
Lee et al. (1997), Beamon (1998) and Suwignjo et al. (2000) showed that dynamic supply chain practices offer the prospect of more efficient matching suppliers and producers in the face of changing market conditions. Vokurka and Fliendner (1998) identified that customer requires reasonable order fulfilment time when production is changing to new models, or when a high demand peak occurs. In addition, Silveira (1998), Frey (1994) and Lee and Tang (1997) have shown that product variety has increased significantly and increased product and component variety is a significant characteristic of modern competitions. This will in turn reduce the product life cycles dramatically.

Vigorous supply chain coordination between the manufacturer and its suppliers was the focus of various dynamic supply chain analyses in the literature. Coordination (with information sharing in the heart of it) was regarded as a core responsibility for a supply chain manager to explore these coordination gaps and to handle them properly. Piplani and Fu (2005) presented a coordination framework to align the inventory decisions in decentralized supply chains. The authors have shown through a case study that the framework reduces the supply chain inventory holding cost over the existing system by $10.4 \%$. On the other hand, lack of coordination between the manufacturer and their suppliers showed that the supply chain will suffer from "bullwhip effect" which refers to increasing variability of demand further upstream in the supply chain. Dejonckheere et al. (2004) have shown that the bullwhip problem cannot be completely eliminated and it increases as one move up the chain. Thus the authors have introduced a control engineering based measure to quantify these variations and identified that information sharing as the main form of coordination is necessary to reduce order variance at higher levels of the chain. Further work has been carried out by Ouyang (2007) where the author proposed a framework which allows for optimal inventory replenishment policies, through dynamic sharing and utilizing information with customer demand capturing processes.

Sarimveis et al. (2008) has shown that due to the resemblance of supply chains to engineering dynamical systems, control theory has provided a solid background to improve sustainability performance of the systems. The authors also pointed out many alternative control philosophies and identified the advantages, weaknesses and complexities of each of them. Finally they have showed the importance of a joint cooperation between control experts and supply chain managers to introduce more realism to the dynamical models and also for improved supply chain management policies.

Riddalls et al. (2000) focused on the alternative approaches that have been proposed for modeling the dynamics of supply chains. They categorized these models to be continuous time models, discrete event models or classical operational research methods. Each method was then evaluated from a system dynamics perspective. And finally a judgement was made on whether the merits of operational research techniques justify their performance in industry over the continuous time models and discrete event models.

Stalk and Hount (1990) showed that the supply chain dynamics lead to the increase in the cost of the company and the whole chain. Although the cost can vary from one situation to the other, however, they showed that generally the increase in business overheads due to the dynamics is a cube function of the area between the actual response of a company in the chain and a theoretical neutral axis, where demand equal supply.

Modrak (2009) stated that the movement of items through a product distribution network is a complex dynamic process which depends not only on the network's static topology but also on knowledge of how each node stores, handles and forward items. He showed that understanding the behaviour of distribution networks is vital to business process modeling and is challenging because the dynamic properties of such a network cannot be predicted easily from its static topology.

Computer simulations were widely used as an effective method to grasp the impact of supply chain dynamics. Higuchi and Troutt (2004) integrated simulation experiments with queuing theory to capture the interactions between demand and backlogs as a critical factor in supply chain performance. The model proposed by the authors comprised of three components which were market, retail and factory. The authors were optimistic that the model will be helpful to decision makers and planners to assuage short life cycle product introduction problems. In addition, the work of Pidd (1984) incorporated hierarchical feedback processes with dynamic simulations to analyze supply chain interactive performance.

System dynamics has been another alternative for supply chain modeling and analysis of its dynamics. Examples include the work of Umeda (2007) where he described a novel simulation hybrid-modeling framework which integrates discrete event modeling with system-dynamics modeling. The objectives of developing the framework were to simulate feedbacks of supply chain activities in social system mechanisms, to enable management simulation in long time terms and finally to clarify requirement specifications towards supply chain management gaming. In another work, Georgiadis et al. (2005) showed system dynamic methodology as a modeling and analysis tool to tackle strategic issues for food supply chains. They presented guidelines for the methodology and its development for the strategic modeling of single and multi-echelon supply chains. Finally, the authors examined capacity planning policies for the supply chain with transient flows due to market constraints.

An earlier attempt to make an analogy between fluid dynamics and supply chain to explain the relations between the supply network structures and their dynamics was carried by Romano (2009). The main result of this study was developing an interpretation model using supply network structure, business process configuration and time performance in an attempt to unite these factors under one framework. The findings were demonstrated through practical case studies with data collected from Ferdows et al. (2003).

From the previous review, the dynamics of supply chain is still an area for further research. One of the missing aspects in such dynamic analysis relates to the product flow inside the supply chain. Few attempts have been made to predict this behaviour by using dynamic simulation (Helo, 2000; Winker et al., 1991). However, these approaches failed to offer a quantitative metric that can control and navigates the supply chain to help managers take the best decision under any particular circumstances. The proposed product flow number (PFN) presented in this paper is a novel metric that predicts the product flow nature across a dynamic supply chain network by assigning some numerical values. An analogy has been made to map the dynamics of the fluid flow across a pipe to the product flow across a supply chain. The new metric can act as a very useful planning and control tool to better manage supply chain dynamics among industries.

\section{Proposed product flow number (PFN)}

The proposed metric is based on Reynolds number where the authors attempt to map the dynamics foundation of fluid mechanics to better understand and manage the dynamics in supply chain. In fluid mechanics the Reynolds number $\left(R_{e}\right)$ can be defined as the ratio of inertial forces $\left(\rho v^{2}\right)$ to viscous forces $(\mu v / L)$ and consequently quantifies the relative importance 
of these two types of forces for given flow conditions (Reynolds, 1983).

$R_{e}=v L \frac{\rho}{\mu}$

\subsection{Proposed product flow number (PFN)}

The proposed is a dimensionless number which is defined in Eq. (2) as

Product flow number $=\frac{\text { Total order quantity } * \text { Number of suppliers } * \text { number of available product configurations } * \text { characterization factor }}{\text { production rate } * \text { delivery time }}$

$$
=\frac{Q_{t} * n * C * m}{r * t}
$$

where $L$ is called 'characteristic length' and depends on the physical structure of the means through which fluid flows (e.g. it is equal to the pipe diameter if the cross section is circular), $\rho$ is the fluid density, and $\mu$ is the absolute dynamic fluid viscosity. The Reynolds number is used to determine whether a flow will be laminar or turbulent.

For low values of $R_{e}$ the flow is laminar where viscous forces are dominant and is characterized by smooth, constant fluid motion. Turbulent flow occurs at high Reynolds numbers and is dominated by inertial forces, which tend to produce flow instabilities. For circular pipes the Reynolds number is generally accepted to be within 2300 for a laminar flow, values from 2300 to 4000 are said to be transitional flow and for values greater than Reynolds number 4000, the flow is said to be turbulent (Batchelor, 2000).

In this study, the authors assume that the product flow in a supply chain is similar to fluid flow in a circular pipe. Thus where $Q_{t}$ is total order quantity (pcs), $n$ is number of suppliers, $c$ is number of available product configurations, $m$ is characterization factor, $r$ is production rate (pcs/month) and $t$ is the delivery time of the product (month).

Reynolds number is important in analyzing any type of flow when there is substantial velocity gradient (i.e. shear). It indicates the relative significance of the viscous effect compared to the inertia effect. Since supply networks can be thought of as the means through which material and information flow, we can export the fluid dynamics explanation of the fluid flow to the supply chain network context which will determine a relation between total order quantity, number of suppliers, number of available product configurations, characterization factor, production rate and delivery time.

In this study the inertial force is defined in Eq. (3) as

And, the viscous force is defined in Eq. (4) as

Inertial force $=\frac{\text { Total order quantity } * \text { Number of suppliers } * \text { Number of available product configurations }}{\text { Production rate }}=\frac{Q_{t} * n * c}{r}$

product flow dynamics can be laminar (which means smooth and easily controlled), transitional or turbulent flow (which means it is experiencing undesirable dynamics). The product flow number will work same as Reynolds number to decide on the nature of the flow dynamics. The new product flow number will focus on an apparel manufacturing industry in an attempt to demonstrate and validate the new approach. The general application of the new developed metric can be extended to other industries; however, this will be carried out in future work.

\subsection{Assumptions of the proposed product flow number (PFN)}

The proposed product flow number is based on the following assumptions:

a. Total order quantity $Q_{t}$ in period $t$ (the difference between demands in periods $t$ and $t-1)$ is known where $Q_{t}>0$.

b. The fabric factor $(f)$ and garments factor $(g)$ should be greater than zero. $f>0$ and $g>0$.

Because if any of these two factors are zero; there will be no production and hence there will be no product flow in the supply chain network. Fabric factor $(f)$ and garments factor (g) are the two most important characterization factors for a particular apparel product. The value of fabric factor $(f)$ increases depending on the complexity of fabric used for the product. Similarly, the value of garments factor $(g)$ increases depending on the complexity of the production layout.

c. The production rate $(r)$ is considered as the average number of products the manufacturer can produce per month from one production line. Also, the total working days in the month has been considered as twenty five days/month. The working hours are eight hours/day (excluding 1 hour lunch break).
Viscous force $=\frac{\text { Delivery time }}{\text { Characterization factor }}=\frac{t}{m}$

By definition an inertial force occurs only when the object is accelerated by a force. In this study the parameters defined in Eq. (3) are regarded as inertial force. By increasing these parameters for a particular product its supply chain network apprehends a pushing force which accelerates the dynamicity of the product. For example, if the number of available product configurations is increased, then there will be more product variety which will accelerate dynamics throughout the supply chain network. A similar phenomenon occurs when increasing the production rate since supply chain network activities will also need to be increased to feed the production line which will in turn generate more supply chain dynamics for that product.

On the other hand, a viscous force implies the resistance of a fluid to flow, caused by its internal friction, which makes it resist slowing past a solid surface and makes layers of the fluid resist flowing past other layers. The two parameters delivery time $(t)$ and characterization factor $(m)$ defined by Eq. (4) are regarded as viscous force for the product flow in the supply chain. For example, if the value of characterization factor increases for a particular product then this resists a smooth flow of the product across the supply chain network due to its complexity especially if compared to a simple product. Likewise, if the delivery time increases for a specific product then this will lead to an increase in the immobility of that product.

Laminar flow occurs at low Reynolds numbers where viscous forces are dominant and is characterized by smooth, constant fluid motion, while turbulent flow occurs at high Reynolds number and is dominated by inertial forces which tend to produce random eddies, vortices and other flow instabilities. The same phenomenon occurs for the product flow in the supply chain. The laminar product flow (at low product flow number) 
indicates that production rate and delivery time for a product are dominant (the production can meet the demand in a timely manner, i.e. enough products and enough time) and thus the supply chain network is characterized by smooth and constant production flow. Turbulent product flow occurs at high product flow number when it is dominated by inertial forces represented by total order quantity, number of suppliers, number of available product configurations and characterization factor. The reason behind such analogy is that the previous factors tend to make the supply chain more complex and uncertain.

The characterization factor $(m)$ is the sum of the most important factors that share in describing the product configuration. Since this study deals with apparel products, the authors identified four most important factors in that product and thus the characterization factor can be defined using :

$$
\begin{gathered}
\text { Characterization factor }(m) \\
=\text { fabric factor }+ \text { garments factor }+ \text { print factor } \\
\quad+\text { embroidery factor }+ \text { washing factor, } \\
m=f+g+p+e+w
\end{gathered}
$$

where $f$ is fabric factor, $g$ is garments factor, $p$ is print factor, $e$ is embroidery factor and $w$ is washing factor.

From Eq. (2), it is clear that the total order quantity $\left(Q_{t}\right)$, number of suppliers $(n)$, number of available product configurations $(c)$ of the product and the characterization factor $(m)$ has proportional relationship with product flow number while production rate $(r)$ and delivery time $(t)$ has inverse proportional relationship with product flow number. These relationships are important to understand the role of the various parameters of product flow number on supply chain planning and control. These parameters are further described.

To complete the flow dynamics analogy, it is important to point out that the analysis presented in this paper for the product flow is bounded within the apparel facility itself and the core contributing suppliers. This means that this analysis does not include all the other supply chain echelons upstream and downstream of that portion of the supply chain pipe. A summary of this boundary consideration is depicted in Fig. 1.

\subsection{Insights on input parameters}

In this subsection a brief description of the input parameters and information that are assumed to be available are presented.

\subsubsection{Total order quantity $\left(q_{t}\right)$ and delivery time $(t)$}

Total order quantity, $Q_{t}$ is the total number of products that need to be produced within a specified time period. For example if a buyer orders 100,000 pcs of garments to be produced within four months this means that the manufacturer needs to deliver that quantity to the buyer after four months. It is important to note that having the proper adjustment between the order quantity and delivery time can affect the supply chain dynamics. For example, if a number of garments need to be produced in five months then the product flow pattern will be different when compared to the same number of garments that need to produce within three months. So, these two input parameters plays an important role in determining the product flow number and have the capability to significantly change the flow pattern from laminar to turbulent or vice versa.

\subsubsection{Number of suppliers ( $n$ )}

This number indicates the total number of supplier in a supply chain network. The number of supplier plays an important role in the flow pattern. For example, if the raw material of the product comes from fifteen different suppliers and the semi finished product passes through another three to four suppliers (as we will observe in the apparel supply chain network) then this network configuration will be much more complex when compared to other products for which their raw material comes from only ten different suppliers and the semi finished product passes through another one or two suppliers to have the final product. It is clear that if there are more suppliers involved, the lead time (the time between ordering and receiving a single product) of the product will be higher and vice versa. Thus, the overall supply chain planning strategy should be different from one product to the other based on the number of suppliers involved.

\subsubsection{Number of available product configurations (c)}

The number of available product configurations also increases the value of product flow number. For example, if the garments need to be produced in three different colors, this will be different from the case where the same garments need to be produced with six different colors. If the number of colors of the garments increases, then the dyeing department need to produce six more batches instead of three batches. In addition, if the garments contain printing, embroidery or washing facilities, then in each case the suppliers need to account for these different configurations of the garments. Finally on the production floor level, if one color garments changed into another color (new configuration), then the threads, labels (care and batch) and other necessary set up will also change and this will in turn reduces the quantity of production and will prolong delivery time.

\subsubsection{Production rate ( $r$ )}

Production rate refers to the number of product that can be produced in one month using one production line with units of pcs/month. If there are more production lines available for this product, then simply multiply the number of production lines with the monthly production rate. Production rate is an important factor that can reduce the product flow number (PFN) significantly.

\subsubsection{Characterization factor $(m)$}

The characterization factor integrates the most significant parameters that affect the flow of the product on the production line. For each of the selected factors mentioned earlier, a value between 0 and 5 has been assigned based on the level of difficulty to perform the operation. It is important to note that the selected metric is based on the authors experience with apparel industry and is used to highlight the impact of different characterization factors' levels and types on the overall flow of the product in the supply chain. This subjective selection of the metric values can be

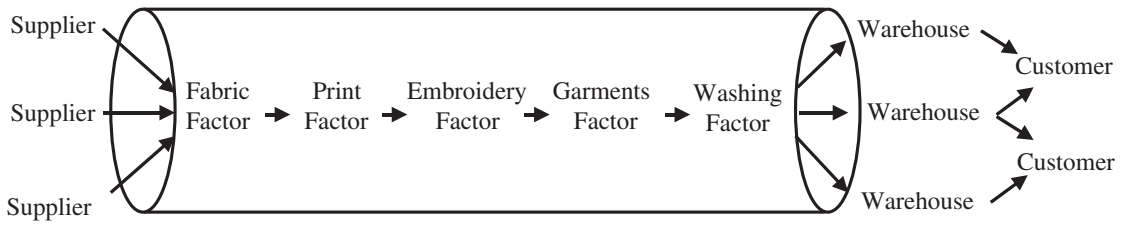

Fig. 1. Selected supply chain pipe portion and its boundaries. 
further investigated (in later research) to have more exact ones; however, the overall analysis is not affected with any proportional difference in these values. The values are explained in Table 1.

Since fabric factor $(f)$ and garments factor $(g)$ cannot hold a value of zero, the characterization factor $(m)$ range will be $2 \leq m \geq 25$. A print factor value of zero means there is no print work in the garments; hence the garments will not flow to the print supplier. A print factor value of one means that there is an embellishment work in the garments which is very basic (say discharge print) and the printing area is very small. Hence it will require less printing time from the printing supplier. Furthermore, a print factor five means that, there is a lot of printing work in the garments (e.g. flock and discharge print in the front side and a rubber print in the back side) and thus to accomplish these types of operations the printing supplier will require more time. This will definitely affect the dynamics of the supply chain. Also, most of the times the rejection rate in these cases becomes higher and the manufacturer needs to reorder replacement for the rejected parts. Similarly for garments factor $(g)$ a value between 0 and 5 has been assigned based on the level of difficulty to perform the production operation. For example if the shape of a neck in a $\mathrm{t}$-shirt consisted of $\mathrm{V}$-neck instead of a round neck, then it will be much more complex for an operator to perform such an operation. Such complexity in design also hampers smooth flow of production and enhances rejection rate. Thus an efficient supply chain

Table 1

Values description for the factors integrated in the characterization factor.

\begin{tabular}{lll}
\hline $\begin{array}{l}\text { Intensity } \\
\text { ofImportance }\end{array}$ & Definition & Description \\
\hline 0 & No effect & $\begin{array}{l}\text { This value means that the particulars have no } \\
\text { effect and hence are not produced in actual } \\
\text { practice. } \\
\text { This value means that the particulars have low } \\
\text { effect and hence signifies easy production. } \\
\text { This value means that the particulars have } \\
\text { moderate effect in terms of production. }\end{array}$ \\
3 & Low effect \\
Toderate & $\begin{array}{l}\text { Sffect } \\
\text { Strong effect }\end{array}$ & $\begin{array}{l}\text { This value means that the particulars have strong } \\
\text { effect in terms of production. } \\
\text { This value means that the particulars have very } \\
\text { strong effect in terms of production. } \\
\text { This value means that the particulars have } \\
\text { extremely important influence in terms of } \\
\text { production. }\end{array}$ \\
\hline
\end{tabular}

manager will never evaluate the two operations (V-neck versus round neck) as a same digit. Thus higher the garments factor $(g)$ means the more complex the garment is in terms of production. Similar scenarios are true for all other factors as well. It is necessary to identify these factors at the early development stage to help supply chain managers gain an insight about upcoming flow pattern of that particular product.

The authors observed that there is distinct relationship between characterization factor $(m)$ and hourly production rate which is shown in Fig. 2. If the value of the characterization factor $(m)$ increases then it reduces the hourly production rate (pcs/h) of that product. Forty products with different characterization factors $(m)$ at different apparel industries have been studied and hourly production rate of each product has been monitored (see Appendix A for data). By plotting these values into Fig. 2 we have found a mathematical relationship among them and which can be expressed as

Productio production rate $(\mathrm{pcs} / \mathrm{h})=218.7-12.67 \mathrm{~m}$

$$
+0.2385 m^{2}-0.001219 m^{3}
$$

where $m$ is the characterization factor. The figure highlights the adverse effect that the characterization factor has over the production rate. One can use Fig. 2 (if working in the same industry) to determine the hourly production rate if $\mathrm{s} /$ he knows the value of the total characterization factor.

\subsection{Product flow number limits for apparel supply chain dynamics}

After the formulation of the product flow number equation and exploring its different parameters, we started to investigate the product flow number values that decide on the supply chain dynamics. More than forty supply chain cases in the apparel industry were monitored for that purpose. The monitoring process focused on the delivery time as the major performance metric that can describe many of the dynamical characteristics of the supply chains. Of all the factors that influence a customers desire to remain loyal to the manufacturer, consistent and on time delivery of their orders stand as a major ones. A performance level of $95 \%$ was selected to describe the acceptable delivery level $(95 \%$ of the required customer order was delivered on time). Fig. 3 shows the delivery performance of the forty observed supply

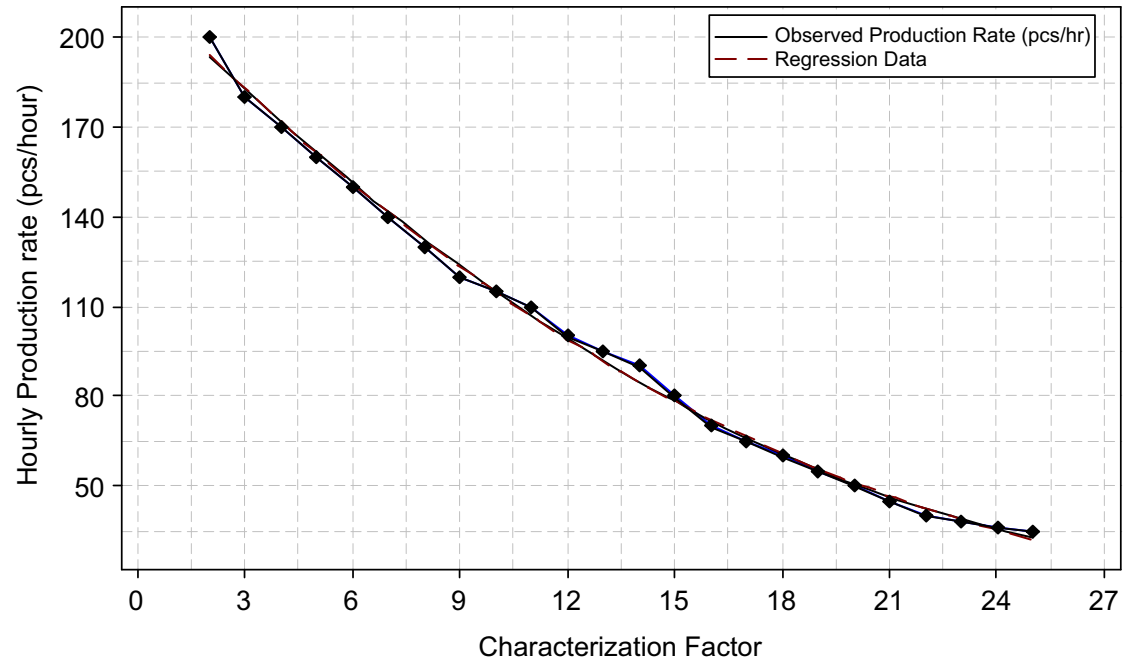

Fig. 2. Relationship between characterization factor and hourly production rate. 


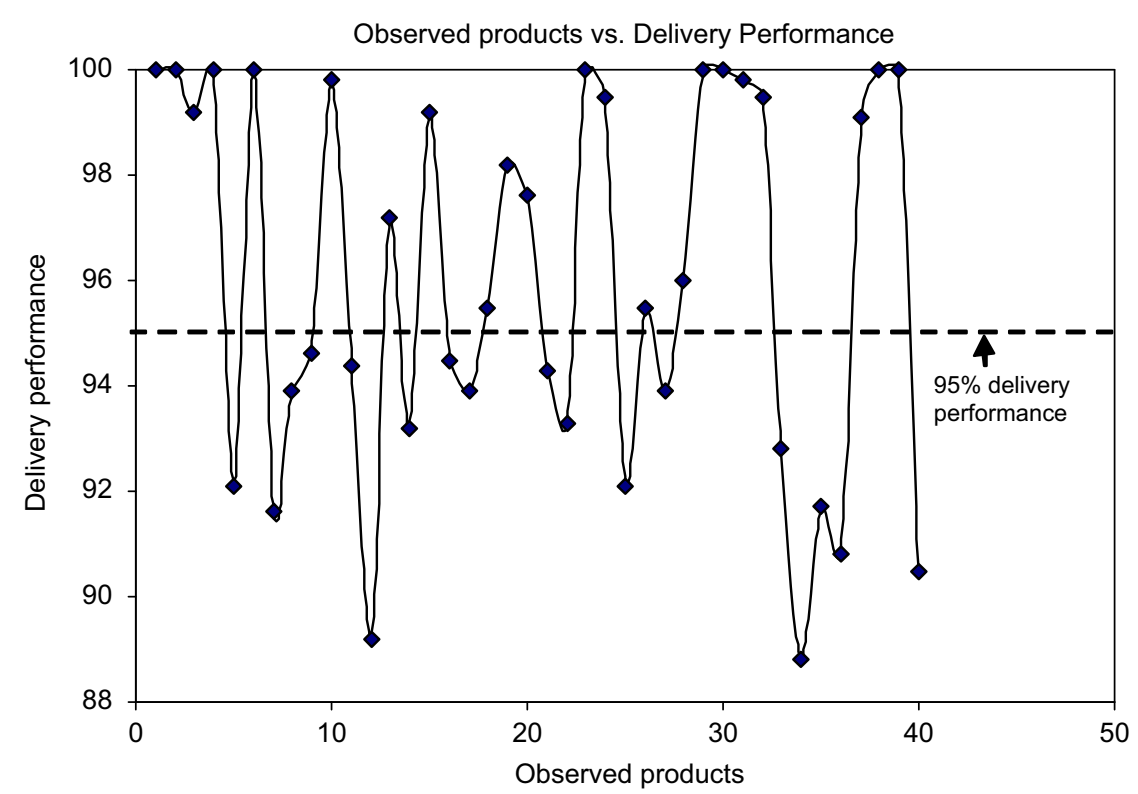

Fig. 3. Delivery performance of the observed products.

chain cases. Numerical calculations of these forty case studies data are shown in Appendix B.

Examining the product flow number of those supply chain cases that had an acceptable delivery performance and those who failed to meet the required level, it was observed that they can be categorized into three zones. For product flow number up to 2300 , the product flow nature can be treated as laminar, while the product flow number greater than 2300 and up to 4000, the product flow nature can be treated as transitional, and finally with product flow number greater than 4000 , the product flow nature can be treated as turbulent. The reason for introducing a transitional zone between laminar and turbulent zones was to recognize that those supply chains cases which failed to meet the required delivery target are not equally treated. In real practice, managers need to know the relative degree of bad performing supply chain plans or configurations to plan for prioritized corrective actions. This will be further demonstrated in this study. Hence, in this paper we propose the following product flow number dynamic limits:

PFN $\leq 2300$ (laminar product flow)

$300 \leq \mathrm{PFN} \leq 4000$ (Transitional product flow)

PFN $>4000$ (Turbulent product flow).

It is also important to note here that in this observational analysis, the considered dynamic limits are calculated with respect to taking the delivery time as the major performance metric and $95 \%$ as a target service level. Considering other performance metrics at different target levels will lead to different dynamic limits for product flow in apparel supply chain. Such analysis will be explored in further research.

Table 2 summarizes important facts about the forty cases studied and used to further support the proposed product flow number dynamic limits.

From Fig. 2, Table 2, and Appendix B data, it is shown that the eighteen cases with delivery performance less than $95 \%$ have their product flow number fall into either transitional or turbulent zone. In comparing the cases with acceptable delivery performance and those with unacceptable performance one can note
Table 2

Summary of forty apparel case studies.

\begin{tabular}{|c|c|c|}
\hline Parameters & $\begin{array}{l}\text { Products that fall in the } \\
\text { Transitional/Turbulent Zone }\end{array}$ & $\begin{array}{l}\text { Products that fall in } \\
\text { the Laminar Zone }\end{array}$ \\
\hline Average order quantity & 259,300 pcs & 128,100 pcs \\
\hline Average lead time & 4 months & 5 months \\
\hline $\begin{array}{l}\text { Average number of } \\
\text { suppliers }\end{array}$ & 22 & 19 \\
\hline $\begin{array}{l}\text { Average number of } \\
\text { product } \\
\text { configurations }\end{array}$ & 5 & 5 \\
\hline Average production rate & $17,870 \mathrm{pcs} / \mathrm{month}$ & 21,900 pcs/month \\
\hline $\begin{array}{l}\text { Average } \\
\text { characterization } \\
\text { factor }\end{array}$ & 14 & 11 \\
\hline $\begin{array}{l}\text { Average product } \\
\text { delivery performance }\end{array}$ & $92.533 \%$ & $98.914 \%$ \\
\hline
\end{tabular}

the following. The eighteen cases with unacceptable delivery performance, produced with an average of order quantity of 259,300 pcs, with an average lead time of four months and an average production rate of 17,870 pcs per month from one production line. These eighteen products routed on an average of twenty two different suppliers and then reached to the manufacturer. The average characterization factors of these eighteen products were calculated as fourteen. On the other hand, the twenty two cases greater than 95\% delivery performance produced with an average of 128,100 pcs, with an average lead time of five months and an average production rate of 21,900 pcs per month from one production line. These twenty two products routed on an average of nineteen different suppliers and then reached to the manufacturer. Also the characterization factors of these twenty two products were measured on an average of eleven. Based on this comparison, a tentative reason for transitional and turbulent product dynamics in a supply chain and thus bad delivery performance is related to the complex parameters of the products involved in theses supply chain cases. Further explanation of the impact of these parameters of the supply chain dynamical performance is explained in the next section. 


\section{Industrial application}

In this section, a simple style in an apparel industry is considered and its product flow number is calculated. Further analysis is conducted by changing different input parameters and examining the product flow number. This analysis includes various scenarios for different styles with different order quantity, number of suppliers, number of colors, production rate and with different characterization factors. Each scenario represents a supply chain management scenario where the product flow number can guide the planners to various problems and solutions required to better manage the dynamics involved in each scenario.

Fig. 4 shows the basic style considered in this study. The supply chain network for this product is shown in Fig. 5. As mentioned earlier, only the prime suppliers of this style have been depicted.

For example, the buyer ordered 100,000 pcs of garments with five different colors to be delivered within four months. The garment has all the embellishments (print and embroidery) but they are very basic. The construction of the garment is simple and the final garment need to be washed before packed. Twenty one major suppliers of the style have been identified.

The product flow number calculation for this basic style case is shown in case 1 in Appendix C, Table C1. The PFN value of 407 signifies that the flow pattern of this case is laminar, which means that the style production process will be under control and all the stages of the supply chain network will experience smooth flow of production. In the first analysis, we will assume that for the same

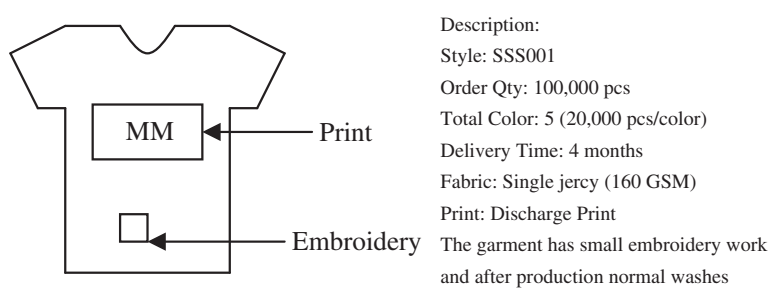

Fig. 4. Sample style with its description. style, we will have to produce with a delicate fabric, there is a lot of embellishment works in the garment and some extra features have been added to the garment which will increase the garments factor $(g)$ value as well. Thus, the total characterization factor will increase from five to sixteen. This will decrease the production rate $r$, and the new rate can be determined using Eq. (6). The order quantity $\left(Q_{t}\right)$, the number of available configurations $(c)$ and number of suppliers $(n)$ of the garment are kept constant. The product flow number for this second case (case 6 in Appendix $C$ Table C1) is calculated to be 2915 which means that the product flow now becomes transitional. This implies that the supply chain planning managers need to think about this specific style and the dynamics it will generate. It will behave differently as compared to the previous case. To examine the impact of the characterization factor more, case 9 in Appendix C, Table C1 will present the inclusion of more features which will result in higher product flow number of 6808 . This indicates that product flow pattern within the supply chains will have undesirable dynamics leading to a non smooth flow. There will be lower overall supply chain productivity and delivering the products to the buyer on time will require more attention and better supply chain management. Finally case 10 in Appendix C, Table C1 shows the greatest impact of characterization factor $(m=25)$ over product flow number while keeping the other factors as constant. The PFN for this case we calculated to be 10,265. Fig. 6(a) depicts the effect of characterization factor on product flow number.

Fig. 6(b) shows the effect of order quantity on product flow number. In this analysis, the characterization parameters are kept constant as well as the number of suppliers and number of available configurations. The order quantity is varied and the flow conditions are tested. It is shown that as the order quantity increases the flow pattern changes from laminar to transitional and from transitional to turbulent. See Appendix C, Table C2 for detailed analyzing data of the effect of order quantity on product flow number.

Fig. 6(c) highlights the impact of delivery time on the product flow number. The orders quantities as well as the other parameters are kept constant while the delivery time is changed. It is clear that the higher the delivery time, the lower the product flow number and thus the more stable the supply chain network

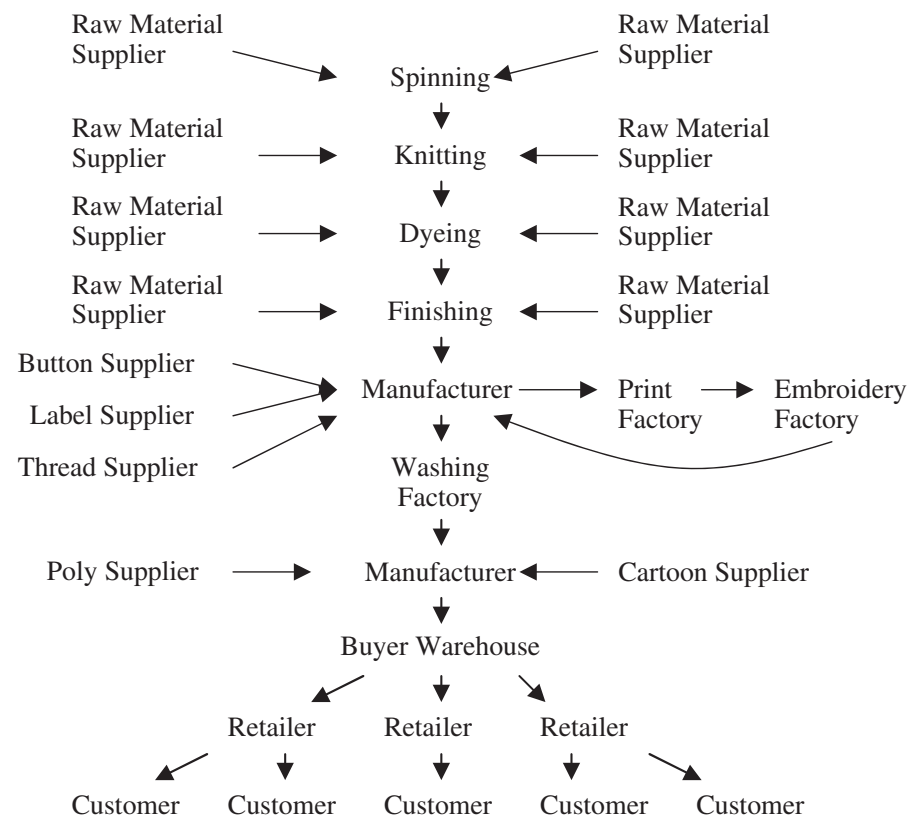

Fig. 5. Supply chain network of the sample style. 
a

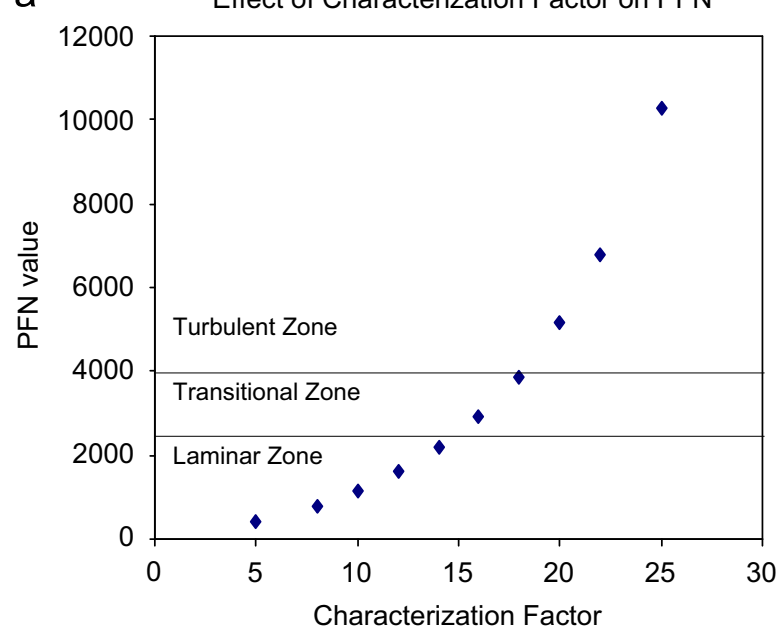

C

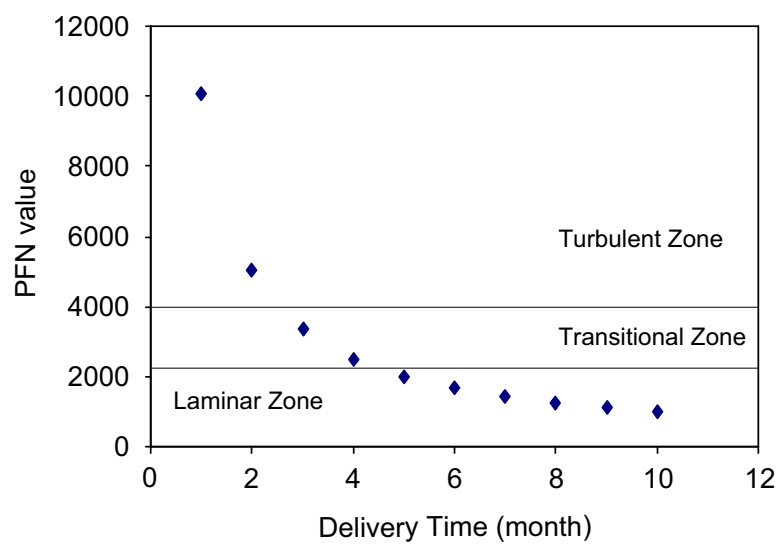

b

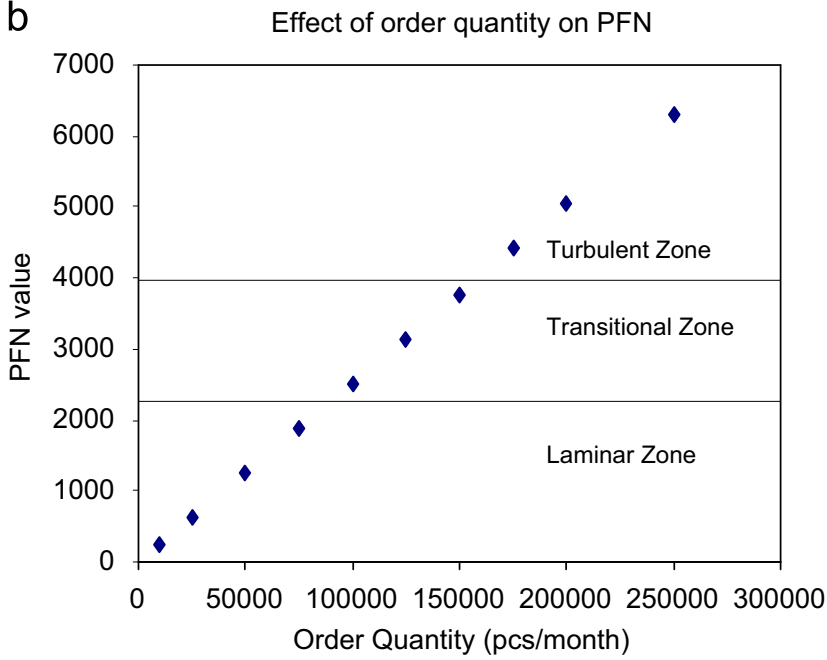

d

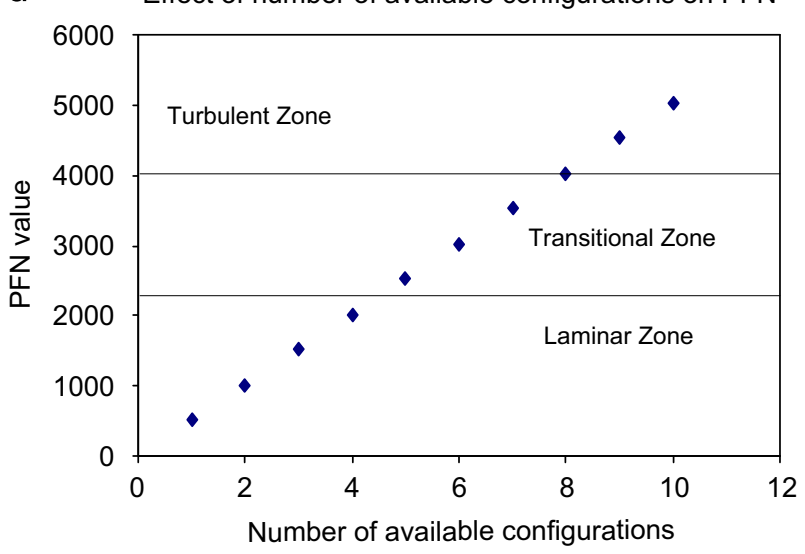

e

Effect of number of supplier on PFN

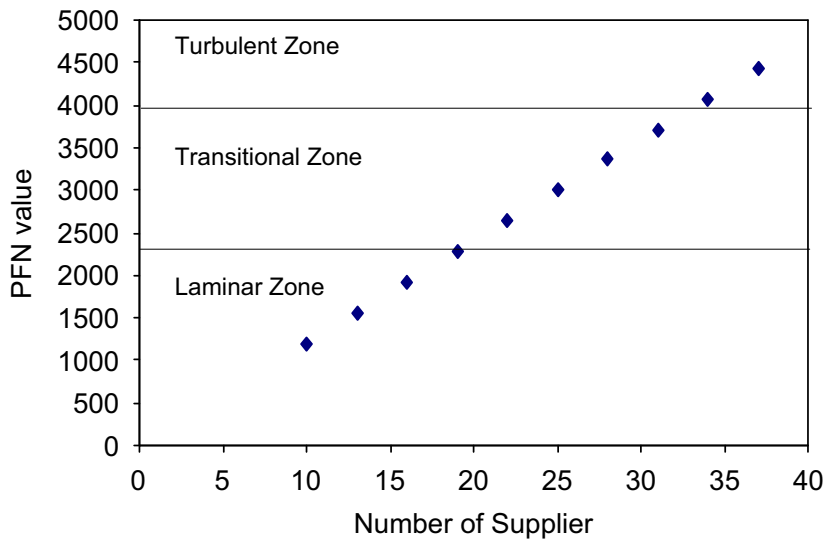

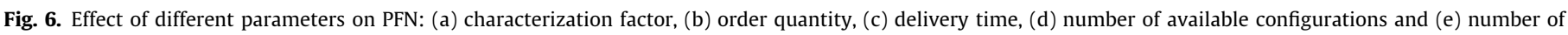
supplier.

will be. See Appendix C, Table C3 for analysis of the effect of delivery time on product flow number.

Fig. 6(d) and (e) shows the effects of the number of available configurations and the number of suppliers on the product flow number. One can observe that as these two parameters increase, the flow changes from laminar to transitional and then to turbulent under different input conditions. The increased number of product configurations as well as the number of suppliers increases the management complexity of the supply chain network. For example, the effort to plan and control the supply chain of a style which has its raw materials coming from twenty five different suppliers is much higher than that of the same style with aggregated lower number of suppliers. If we add the previous case that is not just one style, but it's actually five or six styles, one can realize the other layer of complexity added to the supply chain management problem. From a product flow number perspective this way can lead to a turbulent or undesired dynamics in the product flow. See Appendix C, Tables C4 and C5 for detailed analyzing data of the effect of number of available configurations and number of suppliers on product flow number. 
Finally Fig. 7 summarizes the calculated product flow number for the previously observed forty products with different supply chain network configurations. In general and based on the previous analysis, the reason that these products fall in the transitional and turbulent zones was due to the complexity their configurations as well as their supply chain network. To alleviate this shortage, proper supply chain planning is necessary. The supply chain managers need to understand and calculate the variegated nature of the supply chain dynamics for these products and thus the product flow number will come to play an important role in this area. This is further explained in the coming section.

\section{Guidelines for managing apparel supply chain based on PFN}

The developed product flow number can be used at both the planning phase as well as at the control phase in the apparel supply chain management. Typically, apparel industries deal with multiple products and every product has its own traits. Thus at the planning phase, when customer orders are placed, the planner should calculate the product flow number for each product and based on the calculated PFN, a priority list is set (with products having lower values at the top of the list). The next step will involve managing each product on that list with respect to its PFN value paying extra attention to the coordination among multiple products when it comes to corrective actions required. This is further explained as follows:

If the product flow number is less than 2300 then the current configuration of the supply chain is capable of fulfilling the

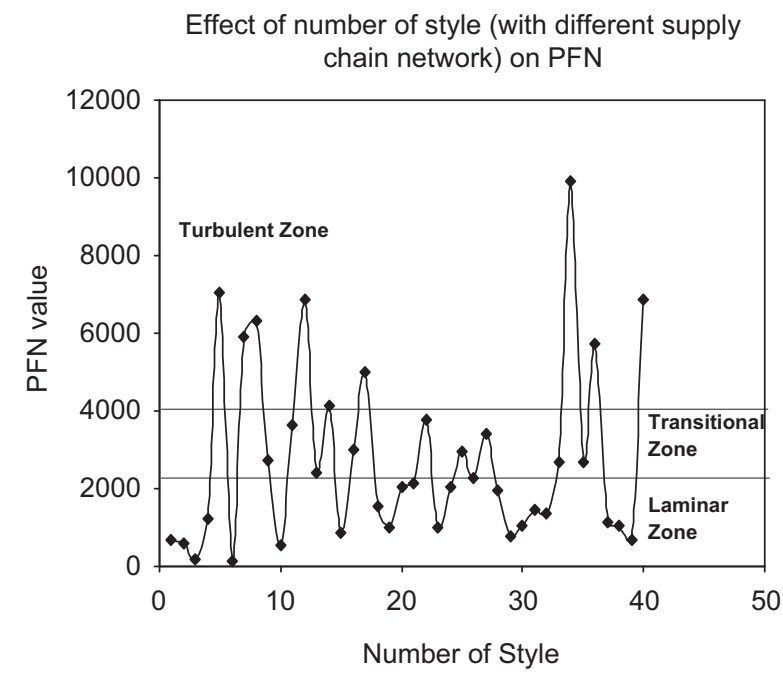

Fig. 7. Calculated product flow number of the selected forty case products. required order. A routine follow up needs to be done in this case until the products reach the warehouse of the buyer.

If the product flow number is found to be between 2300 and 4000 , then this is an indication that the current supply chain configuration is at risk of being unable to fulfill the required order at a timely manner. Proper follow up and extensive planning is required to reduce the product flow number and change that transitional flow to a laminar one. A typical action that the managers can do in this case is to scale the supply chain capacity up. For example, more production lines for this style should be allocated to ensure the smooth flow of supply to its immediate supplier. Another action can be to aggregate the number of raw materials' suppliers who will be involved.

Finally, a product flow number greater than 4000 would indicate that the product flow nature in the supply chain network will be extremely complex. With such undesirable dynamics, planners should think of reconfiguring the supply chain capabilities to be able to meet the customer order. Examples of such reconfigurations are to scale up the production capacity or to change their organizational structure to cope up with such undesirable dynamics. Without such actions together with rigorous planning and follow up then it will be almost impossible to deliver the full quantity of orders to its destination on time. Fig. 8 summarizes the previous planning guidelines based on the product flow number.

The developed metric can also be used at the control level of the apparel supply chain management. The product flow number can be used as tracking tool throughout the supply chain to control its performance and monitor expected delivery time. To illustrate this control aspect the following example is proposed. An order of 100,000 pcs of garments has been placed to the supply chain. The style was highly complicated with different kinds of embellishments, and its characterization factor was calculated to be twenty. For the first month the manufacturer allocated only one production line and calculated its product flow number to be 4200. However, at the beginning of the second month while the manufacturer was still allocating one production line with the same constraints, the product flow number increased to 4725

Table 3

Examples of how PFN calculations are used to control orders in apparel supply chain.

\begin{tabular}{rllllllllllll}
\hline \multicolumn{1}{l}{$Q_{t}$} & $n$ & $t$ & $c$ & $r$ & $f$ & $g$ & $p$ & $e$ & $w$ & $m$ & $P F N$ & Flow \\
\hline 100,000 & 21 & 5 & 5 & 10,000 & 4 & 4 & 4 & 4 & 4 & 20 & 4200 & Turbulent \\
90,000 & 21 & 4 & 5 & 10,000 & 4 & 4 & 4 & 4 & 4 & 20 & 4725 & Turbulent \\
80,000 & 21 & 3 & 5 & 20,000 & 4 & 4 & 4 & 4 & 4 & 20 & 2800 & Transitional \\
60,000 & 21 & 2 & 5 & 20,000 & 4 & 4 & 4 & 4 & 4 & 20 & 3150 & Transitional \\
40,000 & 21 & 1 & 5 & 40,000 & 4 & 4 & 4 & 4 & 4 & 20 & 2100 & Laminar \\
0 & 21 & 0 & 5 & 0 & 4 & 4 & 4 & 4 & 4 & 20 & 0 & Product delivered
\end{tabular}

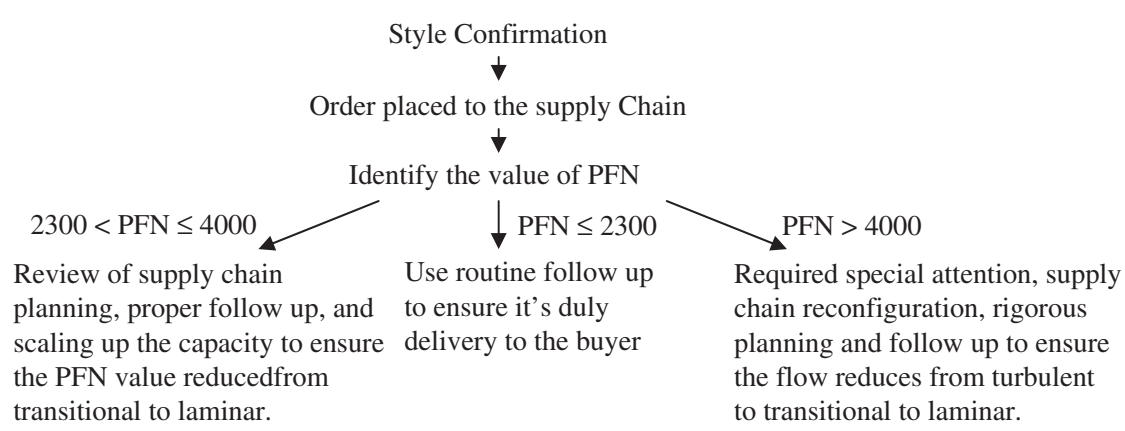

Fig. 8. Planning guidelines based on product flow number (PFN). 
Table A1

Observed hourly production rate $(r)$ against different characterization factor $(m)$ values.

\begin{tabular}{|c|c|c|c|c|c|c|c|}
\hline $\begin{array}{l}\text { Characterization } \\
\text { factor }(m)\end{array}$ & $\begin{array}{l}\text { Production rate }(r) \\
(p c s / h)\end{array}$ & $\begin{array}{l}\text { Characterization } \\
\text { factor }(m)\end{array}$ & $\begin{array}{l}\text { Production rate }(r) \\
(p c s / h)\end{array}$ & $\begin{array}{l}\text { Characterization } \\
\text { factor }(m)\end{array}$ & $\begin{array}{l}\text { Production rate } \\
(r)(p c s / h)\end{array}$ & $\begin{array}{l}\text { Characterization } \\
\text { factor }(m)\end{array}$ & $\begin{array}{l}\text { Production rate } \\
(r)(p c s / h)\end{array}$ \\
\hline 2 & 190 & 22 & 41 & 14 & 85 & 21 & 47 \\
\hline 4 & 171 & 24 & 35 & 20 & 51 & 18 & 60 \\
\hline 7 & 140 & 17 & 66 & 8 & 135 & 22 & 42 \\
\hline 25 & 33 & 22 & 41 & 21 & 48 & 13 & 91 \\
\hline 19 & 56 & 7 & 140 & 2 & 191 & 12 & 95 \\
\hline 13 & 92 & 12 & 96 & 16 & 71 & 15 & 78 \\
\hline 10 & 117 & 21 & 48 & 11 & 105 & 11 & 106 \\
\hline 9 & 124 & 24 & 36 & 5 & 160 & 20 & 51 \\
\hline 20 & 50 & 5 & 162 & 3 & 183 & 2 & 191 \\
\hline 16 & 72 & 19 & 57 & 15 & 77 & 24 & 35 \\
\hline
\end{tabular}

which indicates a more turbulent status for the product flow. As a control action, the manufacturer decided to scale up the capacity and increased the production line to two lines on the third month. This control action reduced the product flow number from 4725 to 2800. On the final month of delivery the manufacturer allocated four production lines to ensure $100 \%$ on time delivery of the required order. It is important to note that although the manufacturer allocated more production lines, it was still having a high product flow number of 2100 which indicates that extra work need to be done to ensure the $100 \%$ on time delivery. Table 3 shows the monthly production status and product flow number calculation for this example. It is clear that the product flow number can navigate the different supply chain phases as a control metric to ensure the proper decisions are taken to fulfill required orders.

\section{Conclusions}

This paper introduced a novel dimensionless metric called product flow number to determine the product flow nature across the supply chain of apparel industries. The product flow number is meant to provide a better understanding for the nature of the product flow across the supply chain. The metric is based on mapping the dynamics of fluid flow across a pipe to product flow across a supply chain. The proposed product flow number metric is function in the total order quantity, number of suppliers, number of available product configurations, the characterization factor of the product, the production rate and finally the delivery time of the product. In addition, the values for product flow dynamic limits were calculated. Numerical analysis for various supply chain scenarios was conducted to examine the impact of the different product flow number parameters on the product flow. Results showed that smooth dynamics within the apparel supply chain can be achieved through scaling production and extending delivery times, and aggregating the number of suppliers while undesirable dynamics are tied to complex product designs and increasing number of suppliers. Finally, the paper demonstrated how the new metric can be used as a planning and control tool to better manage supply chain dynamics in the apparel industry.

The PFN will aid managers of supply chains in various decisions concerning the configuration of their supply chain (e.g. deciding on the number of suppliers, scaling supply capacity, etc) as well as handling various complex product types (e.g. dedicating various resources to specific products, deciding on customer response lead time, etc.). In real supply chain practices, it is normally difficult to fully predict the product flow nature at the time orders are put to the supply chain. Thus, implementing the proposed product flow number can help to eradicate these anxieties and will ensure better flow visibility for better decisions.
Table B1

Examples of number of products (with different supply chain network) on product flow number.

\begin{tabular}{|c|c|c|c|c|c|c|c|c|c|c|c|c|}
\hline Case & $Q_{t}$ & $n$ & $t$ & $c$ & $r$ & $f$ & $g$ & $p$ & $e$ & $w$ & $m$ & PFN \\
\hline 1 & 50,000 & 10 & 3 & 5 & 16,944 & 3 & 3 & 3 & 4 & 1 & 14 & 689 \\
\hline 2 & 25,000 & 13 & 4 & 5 & 12,161 & 4 & 3 & 5 & 3 & 3 & 18 & 601 \\
\hline 3 & 12,000 & 16 & 4 & 4 & 15,640 & 3 & 3 & 3 & 3 & 3 & 15 & 184 \\
\hline 4 & 56,000 & 19 & 5 & 6 & 15,640 & 3 & 3 & 3 & 3 & 3 & 15 & 1225 \\
\hline 5 & 125,000 & 22 & 4 & 6 & 11,141 & 5 & 5 & 3 & 3 & 3 & 19 & 7035 \\
\hline 6 & 12,550 & 25 & 6 & 5 & 19,780 & 3 & 3 & 3 & 0 & 3 & 12 & 159 \\
\hline 7 & 350,000 & 22 & 5 & 4 & 15,640 & 3 & 3 & 3 & 3 & 3 & 15 & 5908 \\
\hline 8 & 260,500 & 21 & 5 & 6 & 15,640 & 3 & 2 & 4 & 3 & 3 & 15 & 6296 \\
\hline 9 & 130,000 & 19 & 4 & 4 & 14,409 & 5 & 5 & 3 & 2 & 1 & 16 & 2743 \\
\hline 10 & 125,600 & 17 & 6 & 5 & 26,396 & 4 & 2 & 1 & 1 & 0 & 8 & 539 \\
\hline 11 & 150,000 & 20 & 3 & 6 & 19,780 & 3 & 3 & 2 & 3 & 1 & 12 & 3640 \\
\hline 12 & 120,000 & 23 & 2 & 6 & 16,944 & 2 & 5 & 5 & 2 & 0 & 14 & 6841 \\
\hline 13 & 300,000 & 22 & 5 & 5 & 24,620 & 4 & 4 & 0 & 1 & 0 & 9 & 2413 \\
\hline 14 & 275,000 & 21 & 4 & 3 & 15,640 & 3 & 3 & 3 & 5 & 1 & 15 & 4154 \\
\hline 15 & 150,000 & 16 & 4 & 4 & 24,620 & 2 & 2 & 2 & 3 & 0 & 9 & 877 \\
\hline 16 & 350,000 & 18 & 6 & 4 & 18,324 & 3 & 3 & 5 & 0 & 2 & 13 & 2980 \\
\hline 17 & 450,000 & 22 & 6 & 5 & 19,780 & 4 & 4 & 2 & 2 & 0 & 12 & 5005 \\
\hline 18 & 600,000 & 26 & 6 & 3 & 30,201 & 2 & 1 & 2 & 1 & 0 & 6 & 1550 \\
\hline 19 & 78,000 & 21 & 3 & 6 & 26,396 & 3 & 3 & 1 & 1 & 0 & 8 & 993 \\
\hline 20 & 85,000 & 24 & 3 & 5 & 19,780 & 2 & 5 & 3 & 2 & 0 & 12 & 2063 \\
\hline 21 & 130,000 & 19 & 3 & 6 & 22,926 & 5 & 4 & 0 & 1 & 0 & 10 & 2155 \\
\hline 22 & 350,000 & 21 & 5 & 5 & 21,313 & 3 & 2 & 2 & 2 & 2 & 11 & 3793 \\
\hline 23 & 220,000 & 23 & 4 & 4 & 30,201 & 2 & 2 & 2 & 0 & 0 & 6 & 1005 \\
\hline 24 & 180,000 & 16 & 3 & 3 & 18,324 & 4 & 5 & 2 & 2 & 0 & 13 & 2043 \\
\hline 25 & 320,000 & 18 & 5 & 5 & 21,313 & 4 & 2 & 3 & 1 & 1 & 11 & 2973 \\
\hline 26 & 230,000 & 27 & 5 & 6 & 26,396 & 2 & 3 & 2 & 1 & 0 & 8 & 2259 \\
\hline 27 & 210,000 & 22 & 6 & 4 & 14,409 & 2 & 2 & 5 & 2 & 5 & 16 & 3926 \\
\hline 28 & 180,000 & 21 & 5 & 5 & 21,313 & 2 & 3 & 4 & 2 & 0 & 11 & 1951 \\
\hline 29 & 50,000 & 16 & 3 & 3 & 15,640 & 5 & 2 & 3 & 2 & 3 & 15 & 767 \\
\hline 30 & 40,000 & 17 & 2 & 6 & 21,313 & 4 & 3 & 2 & 2 & 0 & 11 & 1053 \\
\hline 31 & 75,000 & 19 & 3 & 5 & 19,780 & 2 & 5 & 0 & 1 & 4 & 12 & 1441 \\
\hline 32 & 125,000 & 16 & 3 & 4 & 21,313 & 3 & 3 & 1 & 1 & 3 & 11 & 1376 \\
\hline 33 & 320,000 & 22 & 4 & 5 & 26,396 & 2 & 4 & 1 & 1 & 0 & 8 & 2667 \\
\hline 34 & 450,000 & 23 & 5 & 5 & 15,640 & 2 & 2 & 4 & 4 & 3 & 15 & 9927 \\
\hline 35 & 150,500 & 22 & 3 & 4 & 19,780 & 4 & 4 & 2 & 2 & 0 & 12 & 2678 \\
\hline 36 & 325,000 & 23 & 5 & 4 & 15,640 & 5 & 1 & 3 & 1 & 5 & 15 & 5735 \\
\hline 37 & 50,000 & 24 & 3 & 4 & 18,324 & 3 & 3 & 2 & 5 & 0 & 13 & 1135 \\
\hline 38 & 75,000 & 23 & 3 & 5 & 24,620 & 2 & 3 & 1 & 1 & 2 & 9 & 1051 \\
\hline 39 & 100,000 & 22 & 3 & 6 & 32,232 & 2 & 3 & 0 & 0 & 0 & 5 & 683 \\
\hline 40 & 200,000 & 25 & 3 & 5 & 16,944 & 2 & 3 & 3 & 3 & 3 & 14 & 6885 \\
\hline
\end{tabular}

Future work is required to extend this approach to other manufacturing practices beyond the apparel industry. In addition, more work is required to investigate the characterization factor $(m)$ different aspects to better reflect various product attributes. Considering other performance measures beside delivery time and at various target levels to determine the product flow dynamic limits is an expected extension of this work. Finally, a full sensitivity analysis for the parameters involved in the product flow number would reveal many important relations and guidelines that will help managing the complex dynamics for apparel supply chains. 


\section{Appendix A}

See Table A1 for more details.

\section{Appendix B}

See Table B1 for more details.

Table C1

Effect of characterization factor on product flow number.

\begin{tabular}{rlllllllllllr}
\hline Case & $Q_{t}$ & $n$ & $t$ & $c$ & $r$ & $f$ & $g$ & $p$ & $e$ & $w$ & $m$ & \multicolumn{2}{c}{ PFN } \\
\hline 1 & 100,000 & 21 & 4 & 5 & 32,232 & 1 & 1 & 1 & 1 & 1 & 5 & 407 \\
2 & 100,000 & 21 & 4 & 5 & 26,396 & 1 & 1 & 2 & 2 & 2 & 8 & 796 \\
3 & 100,000 & 21 & 4 & 5 & 22,926 & 2 & 2 & 2 & 2 & 2 & 10 & 1145 \\
4 & 100,000 & 21 & 4 & 5 & 19,780 & 3 & 3 & 2 & 2 & 2 & 12 & 1593 \\
5 & 100,000 & 21 & 4 & 5 & 16,944 & 4 & 4 & 2 & 2 & 2 & 14 & 2169 \\
6 & 100,000 & 21 & 4 & 5 & 14,409 & 4 & 4 & 3 & 3 & 2 & 16 & 2915 \\
7 & 100,000 & 21 & 4 & 5 & 12,161 & 4 & 4 & 4 & 3 & 3 & 18 & 3885 \\
8 & 100,000 & 21 & 4 & 5 & 10,190 & 4 & 4 & 4 & 4 & 4 & 20 & 5152 \\
9 & 100,000 & 21 & 4 & 5 & 8483 & 5 & 5 & 4 & 4 & 4 & 22 & 6808 \\
10 & 100,000 & 21 & 4 & 5 & 6393 & 5 & 5 & 5 & 5 & 5 & 25 & 10,265 \\
\hline
\end{tabular}

Table C2

Effect of order quantity on product flow number.

\begin{tabular}{rllllllllllll}
\hline Case & \multicolumn{1}{l}{$Q_{t}$} & $n$ & $t$ & $c$ & $r$ & $f$ & $g$ & $p$ & $e$ & $w$ & $m$ & PFN \\
\hline 1 & 10,000 & 21 & 4 & 5 & 15,640 & 3 & 3 & 3 & 3 & 3 & 15 & 252 \\
2 & 25,000 & 21 & 4 & 5 & 15,640 & 3 & 3 & 3 & 3 & 3 & 15 & 629 \\
3 & 50,000 & 21 & 4 & 5 & 15,640 & 3 & 3 & 3 & 3 & 3 & 15 & 1259 \\
4 & 75,000 & 21 & 4 & 5 & 15,640 & 3 & 3 & 3 & 3 & 3 & 15 & 1888 \\
5 & 100,000 & 21 & 4 & 5 & 15,640 & 3 & 3 & 3 & 3 & 3 & 15 & 2518 \\
6 & 125,000 & 21 & 4 & 5 & 15,640 & 3 & 3 & 3 & 3 & 3 & 15 & 3147 \\
7 & 150,000 & 21 & 4 & 5 & 15,640 & 3 & 3 & 3 & 3 & 3 & 15 & 3776 \\
8 & 175,000 & 21 & 4 & 5 & 15,640 & 3 & 3 & 3 & 3 & 3 & 15 & 4406 \\
9 & 200,000 & 21 & 4 & 5 & 15,640 & 3 & 3 & 3 & 3 & 3 & 15 & 5035 \\
10 & 250,000 & 21 & 4 & 5 & 15,640 & 3 & 3 & 3 & 3 & 3 & 15 & 6294
\end{tabular}

Table C3

Effect of delivery time on product flow number.

\begin{tabular}{rllllllllllll}
\hline Case & $Q_{t}$ & $n$ & $t$ & $c$ & $r$ & $f$ & $g$ & $p$ & $e$ & $w$ & $m$ & PFN \\
\hline 1 & 100,000 & 21 & 1 & 5 & 15,640 & 3 & 3 & 3 & 3 & 3 & 15 & 10,071 \\
2 & 100,000 & 21 & 2 & 5 & 15,640 & 3 & 3 & 3 & 3 & 3 & 15 & 5035 \\
3 & 100,000 & 21 & 3 & 5 & 15,640 & 3 & 3 & 3 & 3 & 3 & 15 & 3357 \\
4 & 100,000 & 21 & 4 & 5 & 15,640 & 3 & 3 & 3 & 3 & 3 & 15 & 2518 \\
5 & 100,000 & 21 & 5 & 5 & 15,640 & 3 & 3 & 3 & 3 & 3 & 15 & 2014 \\
6 & 100,000 & 21 & 6 & 5 & 15,640 & 3 & 3 & 3 & 3 & 3 & 15 & 1678 \\
7 & 100,000 & 21 & 7 & 5 & 15,640 & 3 & 3 & 3 & 3 & 3 & 15 & 1439 \\
8 & 100,000 & 21 & 8 & 5 & 15,640 & 3 & 3 & 3 & 3 & 3 & 15 & 1259 \\
9 & 100,000 & 21 & 9 & 5 & 15,640 & 3 & 3 & 3 & 3 & 3 & 15 & 1119 \\
10 & 100,000 & 21 & 10 & 5 & 15,640 & 3 & 3 & 3 & 3 & 3 & 15 & 1007 \\
\hline
\end{tabular}

Table C4

Effect of number of available configurations on product flow number.

\begin{tabular}{rllllllllllll}
\hline Case & $Q_{t}$ & $n$ & $t$ & $c$ & $r$ & $f$ & $g$ & $p$ & $e$ & $w$ & $m$ & PFN \\
\hline 1 & 100,000 & 21 & 4 & 1 & 15,640 & 3 & 3 & 3 & 3 & 3 & 15 & 504 \\
2 & 100,000 & 21 & 4 & 2 & 15,640 & 3 & 3 & 3 & 3 & 3 & 15 & 1007 \\
3 & 100,000 & 21 & 4 & 3 & 15,640 & 3 & 3 & 3 & 3 & 3 & 15 & 1511 \\
4 & 100,000 & 21 & 4 & 4 & 15,640 & 3 & 3 & 3 & 3 & 3 & 15 & 2014 \\
5 & 100,000 & 21 & 4 & 5 & 15,640 & 3 & 3 & 3 & 3 & 3 & 15 & 2518 \\
6 & 100,000 & 21 & 4 & 6 & 15,640 & 3 & 3 & 3 & 3 & 3 & 15 & 3021 \\
7 & 100,000 & 21 & 4 & 7 & 15,640 & 3 & 3 & 3 & 3 & 3 & 15 & 3525 \\
8 & 100,000 & 21 & 4 & 8 & 15,640 & 3 & 3 & 3 & 3 & 3 & 15 & 4028 \\
9 & 100,000 & 21 & 4 & 9 & 15,640 & 3 & 3 & 3 & 3 & 3 & 15 & 4532 \\
10 & 100,000 & 21 & 4 & 10 & 15,640 & 3 & 3 & 3 & 3 & 3 & 15 & 5035 \\
\hline
\end{tabular}

Table C5

Effect of number of suppliers on product flow number

\begin{tabular}{cllllllllllll}
\hline Case & $Q_{t}$ & $n$ & $t$ & $c$ & $r$ & $f$ & $g$ & $p$ & $e$ & $w$ & $m$ & $P F N$ \\
\hline 1 & 100,000 & 10 & 4 & 5 & 15,640 & 3 & 3 & 3 & 3 & 3 & 15 & 1199 \\
2 & 100,000 & 13 & 4 & 5 & 15,640 & 3 & 3 & 3 & 3 & 3 & 15 & 1559 \\
3 & 100,000 & 16 & 4 & 5 & 15,640 & 3 & 3 & 3 & 3 & 3 & 15 & 1918 \\
4 & 100,000 & 19 & 4 & 5 & 15,640 & 3 & 3 & 3 & 3 & 3 & 15 & 2278 \\
5 & 100,000 & 22 & 4 & 5 & 15,640 & 3 & 3 & 3 & 3 & 3 & 15 & 2638 \\
6 & 100,000 & 25 & 4 & 5 & 15,640 & 3 & 3 & 3 & 3 & 3 & 15 & 2997 \\
7 & 100,000 & 28 & 4 & 5 & 15,640 & 3 & 3 & 3 & 3 & 3 & 15 & 3357 \\
8 & 100,000 & 31 & 4 & 5 & 15,640 & 3 & 3 & 3 & 3 & 3 & 15 & 3717 \\
9 & 100,000 & 34 & 4 & 5 & 15,640 & 3 & 3 & 3 & 3 & 3 & 15 & 4076 \\
10 & 100,000 & 37 & 4 & 5 & 15,640 & 3 & 3 & 3 & 3 & 3 & 15 & 4436 \\
\hline
\end{tabular}

\section{Appendix C}

See Tables C1-C5 for more details.

\section{References}

Batchelor, G.K., 2000. An Introduction to Fluid Dynamics. Cambridge University Press, Cambridge.

Beamon, B.M., 1998. Supply chain design and analysis: models and methods. International Journal of Production Economics 55, 281-294.

Dejonckheere, J., Disney, S.M., Lambrecht, M.R., Towill, D.R., 2004. The impact of information enrichment on the bullwhip effect in supply chains: a control engineering perspective. European Journal of Operational Research 153, 727-750.

Ferdows, K., Lewis, M.A., Machuca, J.A.D., 2003. Zara. Supply chain forum. An International Journal 4 (2), 62-67.

Frey, D.N., 1994. The new dynamism. Interfaces 24, 105-108.

Georgidis, P., Vlachos, D., Iakovon, E., 2005. A system dynamics modelling framework for the strategic supply chain management of food chains. Journal of Food Engineering 70, 351-364.

Higuchi, T., Troutt, M.D., 2004. Dynamic simulation of the supply chain for a short life cycle product-lessons from the Tamagotchi case. Computers and Operations Research 31, 1097-1114.

Helo, P.T., 2000. Dynamic modelling of surge effect and capacity limitation in supply chains. International Journal of Production Research 38 (17) 4521-4533.

Joshi, Y.V., 1998. Information visibility and its effect on supply chain dynamics, M.Sc. Thesis. Massachusetts Institute of Technology, USA.

Lee, H.L., Tang, C., 1997. Modelling the costs and benefits of delayed product differentiation. Management Science 43, 40-53.

Lee, H.L., Padmanabhan, V., Whang, S., 1997. Information distortion in a supply chain: the bullwhip effect. Management Science 43 (4), 546-558.

Modrak, V., 2009. Case on manufacturing cell formation using product flow analysis. World Academy of Science, Engineering and Technology 49 519-523.

Ouyang, Y., 2007. The effect of information sharing on supply chain stability and the bullwhip effect. European Journal of Operational Research 182 , 1107-1121.

Pidd, M., 1984. Computer Simulation in Management Science 2nd edition Wiley Chichester 219-226 \& 250-261.

Piplani, R., Fu, Y., 2005. A coordination framework for supply chain inventory alignment. Journal of Manufacturing Technology Management 16 (6) 598-614.

Romano, P., 2009. How can fluid dynamics help supply chain management? International Journal of Production Economics 118 463-472.

Riddalls, C.E., Rennett, S., Tipi, N.S., 2000. Modelling the dynamics of supply chains International Journal of Systems Science 31 (8), 969-976.

Reynolds, O., 1983. An experimental investigation of the circumstances which determine whether the motion of water shall be direct or sinuous, and of the law of resistance in parallel channels. Philosophical Transactions of the Royal Society $174,935-982$.

Sarimveis, H., Patrinos, P., Tarantilis, C.D., Tikanoudis, C.T., 2008. Dynamic modeling and control of supply chain systems: a review. Computers and Operations Research 35, 3530-3561.

Suwignjo, P., Bititci, U.S., Carrie, A.S., 2000. Quantitative models for performance measurement system. International Journal of Production Economics 64 231-241.

Souza, R.d., Zice, S., Chaoyang, L., 2000. Supply chain dynamics and optimization. Journal of Integrated Manufacturing Systems 11 (5), 348-364.

Silveira, D.G., 1998. A framework for the management of product variety. International Journal of Operations and Production Management 18, 271-285.

Stalk, G., Hount, T.M., 1990. Competing Against Time. The Free Press, New York, NY. 
Umeda, S., 2007. Supply Chain integrated discrete-event modeling with system dynamics modeling. International Federation for Information Processing (IFIP). Advances in Production Management Systems 246, 329-336.

Vokurka, R.J., Fliendner, G., 1998. The journey towards agility. Industrial Management and Data Systems 98, 165-171.
Wilding, R., 1998. The supply chain complexity triangle. International Journal of Physical Distribution and Logistics Management 28 (8), 599-616.

Winker, J., Towill, D.R., Naim, M., 1991. Smoothing supply chain dynamics. International Journal of Production Economics 22, 231-248. 